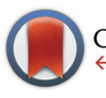

CrossMark \&lick for updates

Cite this: Polym. Chem., 2016, 7, 1642

Received 18th November 2015, Accepted 19th January 2016

DOI: 10.1039/c5py01843a

www.rsc.org/polymers

\title{
Synthesis of high-molecular-weight aliphatic polycarbonates by organo-catalysis $\uparrow$
}

\author{
Jingjiang Sun and Dirk Kuckling*
}

\begin{abstract}
Aliphatic polycarbonates have attracted significant attention for biomedical application over the last few years due to their biodegradability, low toxicity and good biocompatibility. However, in most cases, the use of metal-based catalysts is required for the preparation of aliphatic polycarbonates by the polycondensation method, which is difficult to remove completely from the final polymer. For this reason, our work is focused on the synthesis of high-molecular-weight aliphatic polycarbonates using organocatalysts via a two-step polycondensation of dimethyl carbonate and a linear alkane diol as monomers. A variety of organo-catalysts have been surveyed for the synthesis of aliphatic polycarbonates. The influence of thiourea with mono- or bi-electron acceptor groups as cocatalysts, which were found to activate the carbonyl groups of lactide and trimethylene carbonate in the ring opening polymerization successfully, was investigated in the polycondensation. In summary, high-molecular-weight aliphatic polycarbonates, such as poly(1,4-butylene carbonate) (PBC), poly(1,5-pentamethylene carbonate) (PPC) and poly(1,6-hexamethylene carbonate) (PHC), were successfully prepared with number averaged molar masses $\left(M_{n}\right)$ up to $23000 \mathrm{~g} \mathrm{~mol}^{-1}$, dispersities below 1.8 and high yield of $>80 \%$ under relatively mild operating conditions $\left(T<130{ }^{\circ} \mathrm{C}\right)$ using 4-dimethylaminopyridine (DMAP) as the catalyst. At $170{ }^{\circ} \mathrm{C}$ the poly(1,4-butylene carbonate) with $M_{\mathrm{n}}$ of $52000 \mathrm{~g} \mathrm{~mol}^{-1}$ was synthesized. Additionally, hydroxyl group terminated poly(1,4-butylene carbonate) with $M_{\mathrm{n}}$ up to $17000 \mathrm{~g} \mathrm{~mol}^{-1}$ was obtained and characterized by ${ }^{1} \mathrm{H}$ NMR spectroscopy and ESI-TOF-mass spectrometry. The ratio of end groups $\left(-\mathrm{OH} /-\mathrm{OC}(\mathrm{O}) \mathrm{O}-\mathrm{CH}_{3}\right)$ could be adjusted by using different feed ratios or catalysts.
\end{abstract}

\section{Introduction}

Polycarbonates (PCs) are polymers containing repeating carbonate groups $(-\mathrm{O}-(\mathrm{C}=\mathrm{O})-\mathrm{O}-)$. Aromatic polycarbonates are widely used as engineering plastics ${ }^{1,2}$ because of their attractive mechanical properties, e.g. low moisture absorption, high impact strength, high elastic modulus, creep resistance and good thermal stability. However, compared with traditional aromatic polycarbonates, aliphatic polycarbonates have received little attention because of their poor thermal stability and high susceptibility to hydrolysis. ${ }^{1,3-7}$ Over the last few years, aliphatic polycarbonates have attracted significantly increasing attention for biomedical application, e.g. for the composition of biomedical implants and acting as drug delivery devices, due to their biodegradability, low toxicity and good biocompatibility. ${ }^{1,4,8-11}$ Aliphatic polycarbonates can be prepared through different methods, such as copolymerization

University of Paderborn, Chemistry Department, Warburger Str. 100, D-33098 Paderborn, Germany.E-mail: dirk.kuckling@uni-paderborn.de

$\dagger$ Electronic supplementary information (ESI) available: Procedures for preparation of catalysts and NMR spectra of catalysts and polycarbonates. See DOI: 10.1039/c5py01843a of $\mathrm{CO}_{2}$ and an epoxide (Scheme 1a), ${ }^{12,13}$ which is only suitable for the synthesis of aliphatic polycarbonates in which the carbonate linkages are connected by two carbon atoms, ring opening polymerization of cyclic carbonate monomers (Scheme $1 \mathrm{~b})^{1,14-18}$ and condensation polymerization of dialkylor diphenyl carbonate and aliphatic diols (Scheme 1c). ${ }^{4,19-26}$

The ring opening polymerization of cyclic carbonates is one of the most effective methods to obtain polycarbonates with a high molar mass and low dispersity. ${ }^{20}$ However, cyclic carbonate monomers are very expensive because of their low synthetic yields. Hence, polycarbonates from ring opening polymerization have been mainly investigated for biomedical application. $^{22,27,28}$ The best strategy for large-scale preparation of aliphatic polycarbonates is the two-step condensation polymerization of dimethyl carbonate (DMC) and aliphatic diols with more than three carbon atoms. Oligomers with a molar mass lower than $1000 \mathrm{~g} \mathrm{~mol}^{-1}$ are obtained in the first, initial condensation step, due to the low equilibrium constant. In the second step, polymer chains propagated by transesterification between the hydroxyl and methyl carbonate or two methyl carbonate end groups in the presence of transesterification catalysts, while high temperature and high vacuum are required to remove unreacted monomers and freshly generated byproducts. 


$$
\begin{array}{ll}
\text { 2. step: } \\
\text { condensation polymerization }
\end{array}
$$

Scheme 1 Various methods for the preparation of aliphatic polycarbonates.

The resulting oligomers or polymers have three possible end group compositions, hydroxyl end groups, methyl carbonate end groups or a combination of both (Scheme 1c). ${ }^{19,20,22}$ Recently, Li et al. have reported the preparation of polycarbonates with a high molar mass $\left(M_{\mathrm{n}}\right.$ up to $\left.94000 \mathrm{~g} \mathrm{~mol}^{-1}\right)$ using a novel $\mathrm{TiO}_{2} / \mathrm{SiO}_{2}$-poly(vinyl pyrrolidone)-based catalyst (TSP-44). ${ }^{21}$ Lee et al. have used $\mathrm{NaH}$ as the catalyst to prepare aliphatic polycarbonates with a high molar mass $\left(M_{\mathrm{n}}\right.$ up to $150000 \mathrm{~g} \mathrm{~mol}^{-1}$ ) successfully with the prerequisite that the $[-\mathrm{OH}] /\left[-\mathrm{OCH}_{3}\right]$ ratio of the oligomers generated in the transesterification step is about $1.0 .^{22}$ However, in most cases, the use of metal-based catalysts is required for the preparation of aliphatic polycarbonates by the polycondensation method, which is difficult to remove completely from the final polymer.

For this reason, our work is focused on the synthesis of high-molecular-weight polycarbonates using organo-catalysts via a two-step polycondensation of dimethyl carbonate and a linear alkane diol as monomers. Some organo-catalysts such as guanidines, amidines and tertiary amines have been used in the ring opening polymerization of trimethylene carbonate (TMC) and shown to yield poly(trimethylene carbonate) with a high molar mass $\left(M_{\mathrm{n}}\right.$ up to $\left.72000 \mathrm{~g} \mathrm{~mol}^{-1}\right)$, with low dispersities $\left(D_{\mathrm{M}}=1.04-1.80\right)$ and with well-defined terminal groups. ${ }^{15,16,29}$ Furthermore, thiourea derivatives have been reported for the direct activation of electrophilic substrates via employment of double hydrogen bonding. Hedrick ${ }^{30,31}$ and Dixon $^{32}$ demonstrated that thiourea based bifunctional organo-catalysts effectively activated the ring opening polymerization of cyclic esters. Moreover, Hedrick reported that electrophilic thioureas and nucleophilic bases are not required to be linked in the same molecule. ${ }^{31}$ Kosugi has exploited a 3,5-bis(trifluoromethyl)phenyl and 4-pyrrolidinopyridine (PPY) based zwitter ionic salt organo-catalyst for transesterification
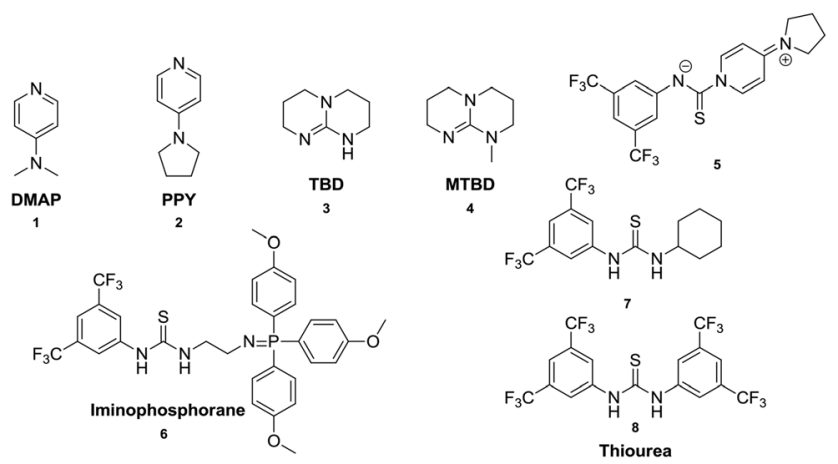

Scheme 2 Organo-catalysts for the synthesis of aliphatic polycarbonates via the polycondensation method.

reactions. ${ }^{33}$ However, there have been few reports about the successful synthesis of aliphatic polycarbonates with highmolecular-weight using organo-catalysts through condensation polymerization of DMC and diols. Picquet and Plasseraud described a route to the synthesis of aliphatic polycarbonates $\left(M_{\mathrm{n}}\right.$ up to $\left.7400 \mathrm{~g} \mathrm{~mol}^{-1}\right)$ using 1- $n$-butyl-3-methylimidazol-2carboxylate (BMIM-2- $\mathrm{CO}_{2}$ ) as a catalyst. ${ }^{4}$

In this work, a variety of organo-catalysts (Scheme 2) have been surveyed for the synthesis of aliphatic polycarbonates. The influence of thiourea with mono- or bi-electron acceptor groups as cocatalysts, which were found to activate the carbonyl groups of lactide and trimethylene carbonate in the ring opening polymerization successfully, was investigated in the polycondensation as well.

\section{Experimental}

\section{Materials}

1,4-Butane diol (99+\%) was purchased from Acros Organics and vacuum distilled using a short path distillation apparatus and dried with $4 \AA$ molecular sieves before use. Other diols $(C>4)$ were dried under vacuum at ambient temperature overnight before use. The catalysts arylaminothiocarbonylpyridinium salt (5), ${ }^{33}$ bifunctional iminophosphorane $(\mathbf{6})^{32}$ and thioureas (7 and 8$)^{34}$ were synthesized as previously reported. Other reagents were commercially available and used as received.

\section{Measurements}

${ }^{1} \mathrm{H}$ and ${ }^{13} \mathrm{C}$ NMR spectra were recorded by using a Bruker $\mathrm{AV}$ 500 spectrometer at $500 \mathrm{MHz}$ and $125 \mathrm{MHz}$, respectively. Chloroform- $d\left(\mathrm{CDCl}_{3}, 99.8 \mathrm{D} \%\right)$, dimethylsulfoxide- $d_{6}$ (DMSO$\left.d_{6}, 99.5 \mathrm{D} \%\right)$ or acetonitrile- $d_{3}\left(\mathrm{MeCN}-d_{3}, 99 \mathrm{D} \%\right)$ were used as solvents for NMR measurements. The molar masses and molar mass distribution $\left(M_{\mathrm{w}} / M_{\mathrm{n}}\right)$ were analyzed by employing a size exclusion chromatography (SEC) system equipped with four consecutive columns (PSS-SDV columns filled with $5 \mu \mathrm{m}$ gel particles with a defined porosity of $10^{6} \AA$, $10^{4} \AA$, $10^{3} \AA$ and $10^{2} \AA$, respectively) and a Shodex RI-detector (RI-101) at $30^{\circ} \mathrm{C}$. 
The system was operated at a flow of $0.75 \mathrm{~mL} \mathrm{~min}^{-1}$ with chloroform as the solvent. Polystyrene standards were used for calibration.

ESI-TOF-mass spectra in the $\mathrm{m} / \mathrm{z}$ range $400-4000$ were measured on a SYNAPT ${ }^{\mathrm{TM}} \mathrm{G} 2$ HDMS $^{\mathrm{TM}}$ from Waters. The mass spectrometric parameters were the following: capillary voltage: $2.5 \mathrm{kV}$; sampling cone voltage: $50 \mathrm{~V}$; extraction cone voltage: $1 \mathrm{~V}$; cone gas flow: $30 \mathrm{~L} \mathrm{~h}^{-1}$; source temperature: $120{ }^{\circ} \mathrm{C}$; desolvation gas flow: $650 \mathrm{~L} \mathrm{~h}^{-1}$; desolvation temperature: $350{ }^{\circ} \mathrm{C}$;

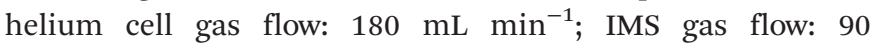
$\mathrm{mL} \min ^{-1}$; IMS wave velocity: $460 \mathrm{~m} \mathrm{~s}^{-1}$; IMS wave height: $40 \mathrm{~V}$. The PBC sample was dissolved in acetonitrile $\left(2 \mathrm{~g} \mathrm{~L}^{-1}\right)$ and then mixed with NaI $0.1 \mathrm{~g} \mathrm{~L}^{-1}$ in methanol in the ratio of $5: 5$ : 990. Data were obtained and processed using Drift Scope 2.4 and Polymerix Software.

\section{General procedure for condensation polymerization of diols and DMC}

In a two-necked flask connected to a Schlenk line with vacuum and argon gas line diol, DMC and organic catalysts were added under an argon atmosphere. The mixture was stirred in an oil bath at $130{ }^{\circ} \mathrm{C}$ until achieving the equilibrium determined by ${ }^{1} \mathrm{H}$ NMR spectroscopy within $2-18 \mathrm{~h}$. Before starting the second step, the flask was equipped with a vacuum distillation apparatus. In the second step the condensation polymerization was carried out under reduced pressure with the oil bath temperature maintained at $130{ }^{\circ} \mathrm{C}$ or increased to $170{ }^{\circ} \mathrm{C}$. The condensation polymerization was conducted overnight. The mixture was then cooled to room temperature and dissolved in chloroform. The polymer was isolated by precipitation in ethanol and dried under vacuum to give a white solid.

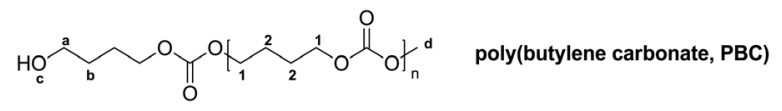

${ }^{1} \mathrm{H}-\mathrm{NMR}\left(500 \mathrm{MHz}, \mathrm{CDCl}_{3}\right)$

$\delta(\mathrm{ppm})=1.65\left(\mathrm{~m}, 3 \mathrm{H},{ }^{\mathrm{b}} \mathrm{CH}_{2},{ }^{\mathrm{c}} \mathrm{OH}\right), 1.76\left(\mathrm{~b}, 4 \mathrm{H},{ }^{2} \mathrm{CH}_{2}\right)$, $3.68\left(\mathrm{t}, 2 \mathrm{H}, J_{\mathrm{HH}}=6.3 \mathrm{~Hz},{ }^{\mathrm{a}} \mathrm{CH}_{2}\right), 3.77\left(\mathrm{~s}, 3 \mathrm{H}, \mathrm{O}^{\mathrm{d}} \mathrm{CH}_{3}\right), 4.15$ (b, $4 \mathrm{H},{ }^{1} \mathrm{CH}_{2}$ )

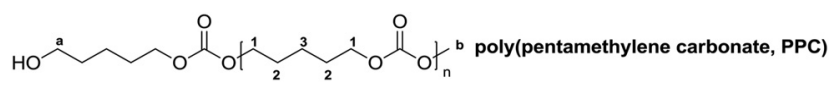

${ }^{1} \mathrm{H}-\mathrm{NMR}\left(500 \mathrm{MHz}, \mathrm{CDCl}_{3}\right)$

$\delta(\mathrm{ppm})=1.46\left(\mathrm{~m}, 2 \mathrm{H},{ }^{3} \mathrm{CH}_{2}\right), 1.70\left(\mathrm{~m}, 4 \mathrm{H},{ }^{2} \mathrm{CH}_{2}\right), 3.65$ $\left(\mathrm{t}, 2 \mathrm{H}, J_{\mathrm{HH}}=6.5 \mathrm{~Hz},{ }^{\mathrm{a}} \mathrm{CH}_{2}\right), 3.77\left(\mathrm{~s}, 3 \mathrm{H}, \mathrm{O}^{\mathrm{b}} \mathrm{CH}_{3}\right), 4.13(\mathrm{t}, 4 \mathrm{H}$, $J_{\mathrm{HH}}=6.6 \mathrm{~Hz},{ }^{1} \mathrm{CH}_{2}$ )

$$
\overbrace{}^{\mathrm{a}} \mathrm{C}_{\mathrm{O}} \mathrm{O}_{1}^{2} \underbrace{1}_{2} \mathrm{ll}_{\mathrm{O}} \mathrm{O}_{\mathrm{n}}^{\mathrm{b}} \text { poly(hexamethylene carbonate, PHC) }
$$

${ }^{1} \mathrm{H}-\mathrm{NMR}\left(500 \mathrm{MHz}, \mathrm{CDCl}_{3}\right)$

$\delta(\mathrm{ppm})=1.40\left(\mathrm{~m}, 4 \mathrm{H},{ }^{3} \mathrm{CH}_{2}\right), 1.67\left(\mathrm{~m}, 4 \mathrm{H},{ }^{2} \mathrm{CH}_{2}\right), 3.63$

$\left(\mathrm{t}, 2 \mathrm{H}, J_{\mathrm{HH}}=6.5 \mathrm{~Hz},{ }^{\mathrm{a}} \mathrm{CH}_{2}\right), 3.76\left(\mathrm{~s}, 3 \mathrm{H}, \mathrm{O}^{\mathrm{b}} \mathrm{CH}_{3}\right), 4.11(\mathrm{t}, 4 \mathrm{H}$, $\left.J_{\mathrm{HH}}=6.8 \mathrm{~Hz},{ }^{1} \mathrm{CH}_{2}\right)$

\section{Results and discussion}

\section{Catalyst screening}

A variety of organo-catalysts such as commercially available pyridines (4-dimethylaminopyridine, DMAP (1) and 4-pyrrolidinopyridine, PPY (2)), guanidines (1,5,7-triazabicyclo[4.4.0]dec5-ene, TBD (3) and 7-methyl-1,5,7-triazabicyclo[4.4.0] dec-5ene, MTBD (4)), bifunctional arylaminothiocarbonylpyridinium salt (5) and iminophosphorane (6) have been used in the condensation polymerization of diols and dimethyl carbonate (DMC). Furthermore, the 4-dimethylaminopyridine (1) was also investigated together with thioureas with mono-(7) and bi(8) electron withdrawing 3,5-bis(trifluoromethyl)phenyl groups as cocatalysts. Such compounds were used in the ring opening polymerization of trimethylene carbonate successfully, ${ }^{15,16,30}$ and it was of interest to test the influence of thiourea in the transesterification step and in the condensation polymerization. In the first step the transesterification reaction of DMC and diols is an equilibrium reaction. According to the Le Chatelier's principle, the chemical equilibrium could only be affected by a change in the temperature or feed ratio. At the equilibrium point the conversions of $-\mathrm{CH}_{2} \mathrm{OH}$ to $-\mathrm{CH}_{2} \mathrm{OC}(\mathrm{O})$ $\mathrm{O}$ - groups should be constant, which is shown in the ${ }^{1} \mathrm{H}$ NMR spectrum of the reaction solution at this point as the constant peak area ratio of unreacted dimethyl carbonate $(3.70 \mathrm{ppm}$ in DMSO- $\left.d_{6}\right)$ and generated byproduct methanol (3.19 ppm in DMSO- $d_{6}$ ) (Fig. 1).

The catalytic activities of various organo-catalyst systems with respect to the transesterification step of 1,4-butanediol (BD) and DMC were evaluated by comparing the necessary time to achieve the equilibrium. The fewer times the system needed, the higher the activity of the system. Table 1 summarizes the results of the different catalyst systems in the transesterification step under an argon atmosphere with a constant feed ratio of $[\mathrm{BD}]:[\mathrm{DMC}]:\left[\right.$ cat.] $=1: 1.2: 0.005$ at $130{ }^{\circ} \mathrm{C}$.

All catalyst systems investigated were active for the transesterification of BD and DMC. It was found that the transesterification reaction was carried out readily $(<1 \mathrm{~h})$ in the presence of pyridine (cat. 3 and 4) and guanidine (cat. 5 and 6) catalysts.

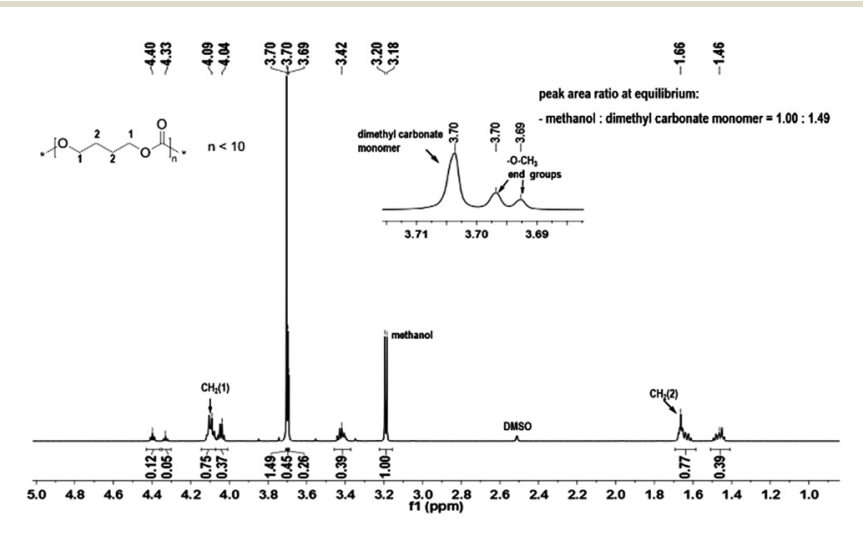

Fig. $1{ }^{1} \mathrm{H}$ NMR spectrum of the reaction solution of BD and DMC using cat. 1 at equilibrium. 
Table 1 Catalyst screening of condensation polymerization of BD and DMC

\begin{tabular}{|c|c|c|c|c|}
\hline Entry & $\begin{array}{l}\text { Catalyst } \\
\text { systems }\end{array}$ & $\begin{array}{l}\text { Time to achieve } \\
\text { equilibrium }^{a}\end{array}$ & $\begin{array}{l}M_{\mathrm{n}}^{b} \\
\left(\mathrm{~g} \mathrm{~mol}^{-1}\right)\end{array}$ & $\bigoplus_{\mathbf{M}}^{b}$ \\
\hline 1 & Cat. 1 & $1.0 \mathrm{~h}$ & 16000 & 1.66 \\
\hline 2 & Cat. 2 & $1.0 \mathrm{~h}$ & 7900 & 2.03 \\
\hline 3 & Cat. 3 & $0.5 \mathrm{~h}$ & 6200 & 2.18 \\
\hline 4 & Cat. 4 & $<0.5 \mathrm{~h}$ & 17000 & 1.77 \\
\hline 5 & Cat. 5 & $3.0 \mathrm{~h}$ & 4100 & 2.40 \\
\hline 6 & Cat. 6 & Overnight & 13000 & 1.68 \\
\hline 7 & Cat. $4+$ cat. 7 & $2.5 \mathrm{~h}$ & 6900 & 2.16 \\
\hline 8 & Cat. 4 + cat. 8 & $3.0 \mathrm{~h}$ & 7500 & 1.80 \\
\hline
\end{tabular}

BD: DMC: cat. $=1: 1.2: 0.005$. Reaction time: 1st step: until equilibrium; 2nd step: overnight. ${ }^{a}$ Determined using ${ }^{1} \mathrm{H}$ NMR spectroscopy. ${ }^{b}$ Determined using SEC in chloroform with PS standards.

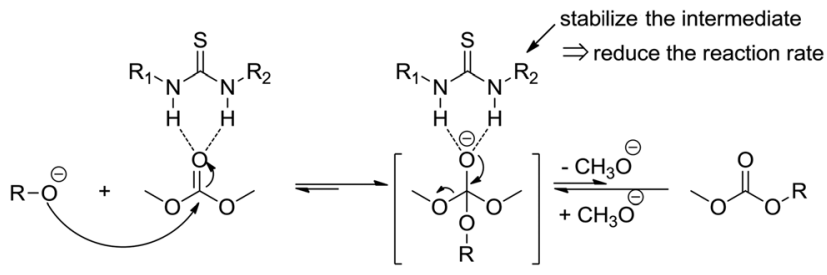

Scheme 3 Possible mechanism of a thiourea catalyzed transesterification reaction.

However, in the same reaction catalyzed either by bifunctional catalysts including thiourea groups (cat. 1 and 2) or by DMAP with mono- or bi-electron withdrawing 3,5-bis(trifluoromethyl) phenyl groups, thiourea (cat. 7 and 8) cocatalysts proceeded much slower.

A proposed mechanism is shown in Scheme 3. The thiourea is able for the direct activation of the carbonyl group by means of double hydrogen bonding. The activation may lead to a more stable intermediate, which may subsequently release the methanol difficultly. This also indicates why the thiourea based catalysts could be used in the ring opening polymerization of cyclic esters or carbonates and inhibiting simultaneously the transesterification side reaction.

Besides the transesterification step, all catalyst systems were also investigated in the polymerization step after achieving the equilibrium in the 1 st step. All catalyst systems were effective for the synthesis of poly(butylene carbonate) from $\mathrm{BD}$ and DMC and polycarbonates were obtained with molar masses higher than $4100 \mathrm{~g} \mathrm{~mol}^{-1}$ and dispersities lower than 2.40 . DMAP (cat. 1) and MTBD (cat. 4) showed the best results with the synthesized polycarbonate having a molar mass up to $17000 \mathrm{~g} \mathrm{~mol}^{-1}$ and dispersity of 1.66 . Also in the polycondensation step, thioureas as cocatalysts retarded the polymerization. Moreover, an experiment without any catalyst was also evaluated at $130{ }^{\circ} \mathrm{C}$ and $170{ }^{\circ} \mathrm{C}$ for 1 st and 2 nd steps, respectively. However, the ${ }^{1} \mathrm{H}$ NMR spectrum after the first step showed that the transesterification reaction between DMC and
BD did not occur. All of the compounds in the reaction flask were distilled off after $30 \mathrm{~min}$ in the second step. This also proved the efficiency of all investigated catalyst systems.

\section{Results of polycarbonate synthesis}

The polymerization temperature and initial feed ratio of diols and DMC are further two important parameters. They can influence the final polymer properties significantly. In order to obtain polycarbonates with higher molar masses, we optimized the polymerization conditions. The initial [BD]:[DMC] ratio was varied from $1: 1.2$ up to $1: 2.0$ and the temperatures in condensation polymerization steps were set from $130{ }^{\circ} \mathrm{C}$ up to $170{ }^{\circ} \mathrm{C}$. The aim of using excess dimethyl carbonate is enhancing the conversion of diols in the 1st step and obtaining oligomers with more methyl carbonate end groups, which are more reactive than hydroxyl end groups in the 2nd step for the transesterification reaction between two polymer chains and thus leading to higher molar masses. The excess of DMC was removed in the 2 nd step. ${ }^{24}$

Table 2 summarizes the most significant results of the polycarbonate synthesis under different polymerization conditions. As shown, $M_{\mathrm{n}}$ increased significantly from $5900 \mathrm{~g} \mathrm{~mol}^{-1}$ to $11000 \mathrm{~g} \mathrm{~mol}^{-1}$, respectively, while the feed ratio changed from $1: 1.5: 0.5 \mathrm{~mol} \%$ to $1: 2.0: 1 \mathrm{~mol} \%$ (entries $1-3$ ), indicating that the methyl carbonate end group is more reactive than the hydroxyl end group in the condensation polymerization step. With the feed ratio of $1: 2.0: 1 \mathrm{~mol} \%, \mathrm{PBC}, \mathrm{PPC}$ and PHC samples with relatively high $M_{\mathrm{n}}$ values up to $23000 \mathrm{~g} \mathrm{~mol}^{-1}$ were obtained in the presence of more reactive catalyst DMAP (entries 9, 11 and 12). Yields were achieved up to $88 \%$, which was calculated by the following equation (eqn (1)).

$$
\text { Yield }=\frac{\frac{\text { mass of purified polymer }}{\text { molecular weight of repeating unit }}}{\text { mole of diol }} \times 100 \%
$$

whereby $116 \mathrm{~g} \mathrm{~mol}^{-1}, 128 \mathrm{~g} \mathrm{~mol}^{-1}$ and $140 \mathrm{~g} \mathrm{~mol}^{-1}$ are the molar masses of repeating units for PBC, PPC and PHC, respectively. Moreover, the $M_{\mathrm{n}}$ values increased with increasing the temperature from $130{ }^{\circ} \mathrm{C}$ to $170{ }^{\circ} \mathrm{C}$ (entries 9 and 10).

In addition, the end group ratio in the resulting polymers could be adjusted by changing the initial feed ratios, catalysts, or polymerization temperatures. The hydroxyl end group content decreases from $86 \%$ to $20 \%$ with the increasing initial concentration of DMC (entries 2 and 3). When the polymerization was conducted using a lower amount of the catalyst, PBC with a higher hydroxyl content (98\% -OH end group) was obtained. The end group composition can also be controlled by using various catalysts due to their different catalytic activities (entries 3 and 9). Using cat. 5 leads to a PBC with a $20 \%$ $-\mathrm{OH}$ end group, while a $\mathrm{PBC}$ with a $68 \%-\mathrm{OH}$ end group could be prepared at the same feed ratio of [diol]:[DMC]:[cat.] = $1: 2: 0.01$, when DMAP (cat. 1) was used. Besides, polymerization temperature is also an important factor in controlling the end group composition. The hydroxyl content decreased from $68 \%$ to $30 \%$ with the temperature increasing from $130{ }^{\circ} \mathrm{C}$ to $170{ }^{\circ} \mathrm{C}$ (entries 9 and 10). By studying the preparation of 
Table 2 Results of polycarbonate synthesis

\begin{tabular}{|c|c|c|c|c|c|c|c|}
\hline & [Diol]: [DMC]: [cat.] & Cat. & $\begin{array}{l}T \text { (2 step) } \\
\left({ }^{\circ} \mathrm{C}\right)\end{array}$ & $\begin{array}{l}\text { Yields } \\
(\%)\end{array}$ & $\begin{array}{l}M_{\mathrm{n}}^{a} \\
\left(\mathrm{~g} \mathrm{~mol}^{-1}\right)\end{array}$ & $D_{\mathrm{M}}{ }^{a}$ & $\begin{array}{l}\text { End groups }^{b} \\
{\left[-\mathrm{OCH}_{3}\right]:[-\mathrm{OH}]}\end{array}$ \\
\hline PBC 1 & $1: 1.5: 0.005$ & Cat. 5 & 130 & 60 & 5900 & 1.85 & $2: 98$ \\
\hline PBC 3 & $1: 2.0: 0.01$ & Cat. 5 & 130 & 65 & 11000 & 1.71 & $80: 20$ \\
\hline PBC 4 & $1: 1.2: 0.005$ & Cat. 1 & 130 & 57 & 16000 & 1.66 & $0: 100$ \\
\hline PBC 5 & $1: 1.2: 0.005$ & Cat. 2 & 130 & 59 & 7900 & 2.03 & $0: 100$ \\
\hline PBC 6 & $1: 1.2: 0.005$ & Cat. 4 & 130 & 61 & 17000 & 1.77 & $0: 100$ \\
\hline PBC 9 & $1: 2.0: 0.01$ & Cat. 1 & 130 & 85 & 23000 & 1.77 & $32: 68$ \\
\hline PBC 10 & $1: 2.0: 0.01$ & Cat. 1 & 170 & 79 & 52000 & 1.77 & $70: 30$ \\
\hline PPC 1 & $1: 2.0: 0.01$ & Cat. 1 & 130 & 77 & 22000 & 1.60 & $43: 57$ \\
\hline PHC 1 & $1: 2.0: 0.01$ & Cat. 1 & 130 & 88 & 23000 & 1.53 & $61: 39$ \\
\hline
\end{tabular}

${ }^{a}$ Determined using SEC in chloroform with PS standards. ${ }^{b}$ Determined using ${ }^{1} \mathrm{H}$ NMR spectroscopy. Reaction time: 1 st step: until equilibrium; 2nd step: overnight.

polycarbonates with defined end group compositions, we found that hydroxyl terminated PBCs, which are of great interest, especially for further terminal group modification, could be obtained by using different catalysts $(0.5 \mathrm{~mol} \%)$ with the initial feed ratio of $[\mathrm{BD}]:[\mathrm{DMC}]<1: 1.2$ (entries 4-8). Among them $M_{\mathrm{n}}$ values determined for the samples using DMAP and MTBD as catalysts (entries 4 and 6) were obtained up to $17000 \mathrm{~g} \mathrm{~mol}^{-1}$ and the dispersities were lower than 1.8. Polymers synthesized using PPY based catalysts (entries 5 and 7) showed lower $M_{\mathrm{n}}$ and higher $\bigoplus_{\mathrm{M}}\left(\bigoplus_{\mathrm{M}}>2\right)$ in contrast to DMAP and MTBD. The lower catalytic activity of PPY based catalysts in the 2nd step is probably reflective of the decreased nucleophilic properties for the transesterification reaction between two methyl carbonate end groups. According to our research results, polycarbonates with a defined $M_{\mathrm{n}}$, end group composition and low dispersity could be achieved by using alterable initial feed ratios, polymerization temperatures and catalysts with different activities.

The ${ }^{1} \mathrm{H}$ and ${ }^{13} \mathrm{C}$ NMR spectra of PBC 9 are shown in Fig. 2. Two multiplet signals at $1.76 \mathrm{ppm}$ and $4.15 \mathrm{ppm}$ are attributed to both the $\mathrm{CH}_{2}$-groups in the polymer backbone. The small signals at $1.64 \mathrm{ppm}$ and $3.67 \mathrm{ppm}$ indicated the existence of a terminal butanol group, while the singlet at $3.76 \mathrm{ppm}$ is assigned to the terminal methyl carbonate group. The ${ }^{1} \mathrm{H}$ NMR spectroscopy indicated that no decarboxylation occurred because no ether linkage $\left(\mathrm{CH}_{2}-\mathrm{O}-\mathrm{CH}_{2}\right)$ at 3.4-3.5 ppm was detected. In addition, by comparing the peak areas of the terminal butanol and methyl carbonate groups, the hydroxyl content could be calculated. For the samples with pure hydroxyl end groups, only two signals at $1.64 \mathrm{ppm}$ and $3.67 \mathrm{ppm}$ were detected, while the singlet peak at $3.76 \mathrm{ppm}$ for $-\mathrm{C}(\mathrm{O}) \mathrm{OCH}_{3}$ was not visible. In the ${ }^{13} \mathrm{C} \mathrm{NMR}$ spectrum, the peaks around $25.14 \mathrm{ppm}$ and $67.25 \mathrm{ppm}$ correspond to $\mathrm{C} 1$ and C2 carbon atoms of the polymer backbone, respectively. The carbonate group is observed at $155.16 \mathrm{ppm}$. Signals of terminal groups are absent in the ${ }^{13} \mathrm{C}$ NMR spectrum.

To determine the influence of polymerization times on the molar mass of PBC, a kinetic study of PBC 9 ([BD]: [DMC]:

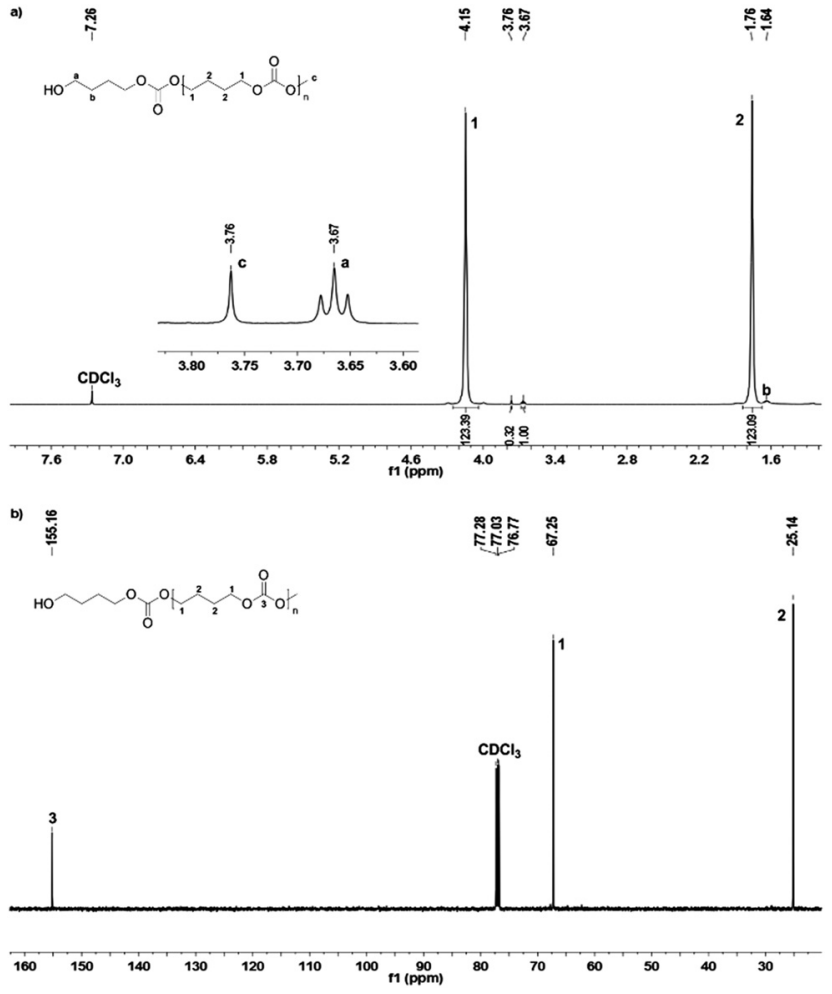

Fig. $2{ }^{1} \mathrm{H}(\mathrm{a})$ and ${ }^{13} \mathrm{C}$ NMR (b) spectra of PBC 9.

[DMAP] $=1: 2: 0.01,130{ }^{\circ} \mathrm{C}$ ) was carried out. Fig. 3 shows the molar mass and molar mass distribution data determined by SEC. The molar mass of the polymer increased rapidly throughout the initial $30 \mathrm{~min}$. After a reaction time of $3 \mathrm{~h}$, a molar mass of $14000 \mathrm{~g} \mathrm{~mol}^{-1}$ was obtained. When the condensation reaction was further conducted, the molar mass increased slowly and finally up to $M_{\mathrm{n}}=23000 \mathrm{~g} \mathrm{~mol}^{-1}$ for $24 \mathrm{~h}$ reaction time. The dispersity values remained below 1.8 during the condensation reaction.

Hydroxyl terminated PBCs (PBC 4-9 in Table 2) have also been investigated by ESI-TOF-MS to determine the end groups. 

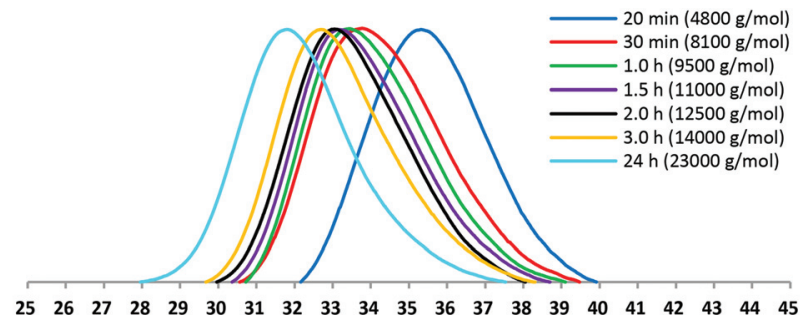

elution volume $(\mathrm{mL})$

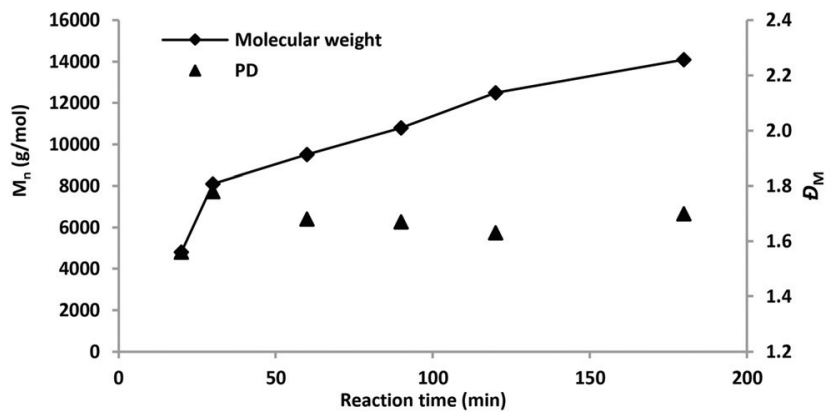

Fig. 3 SEC traces and plot $M_{\mathrm{n}}$ (determined by SEC) and the dispersity values of PBC 9 versus the polymerization time in the 2 nd step.
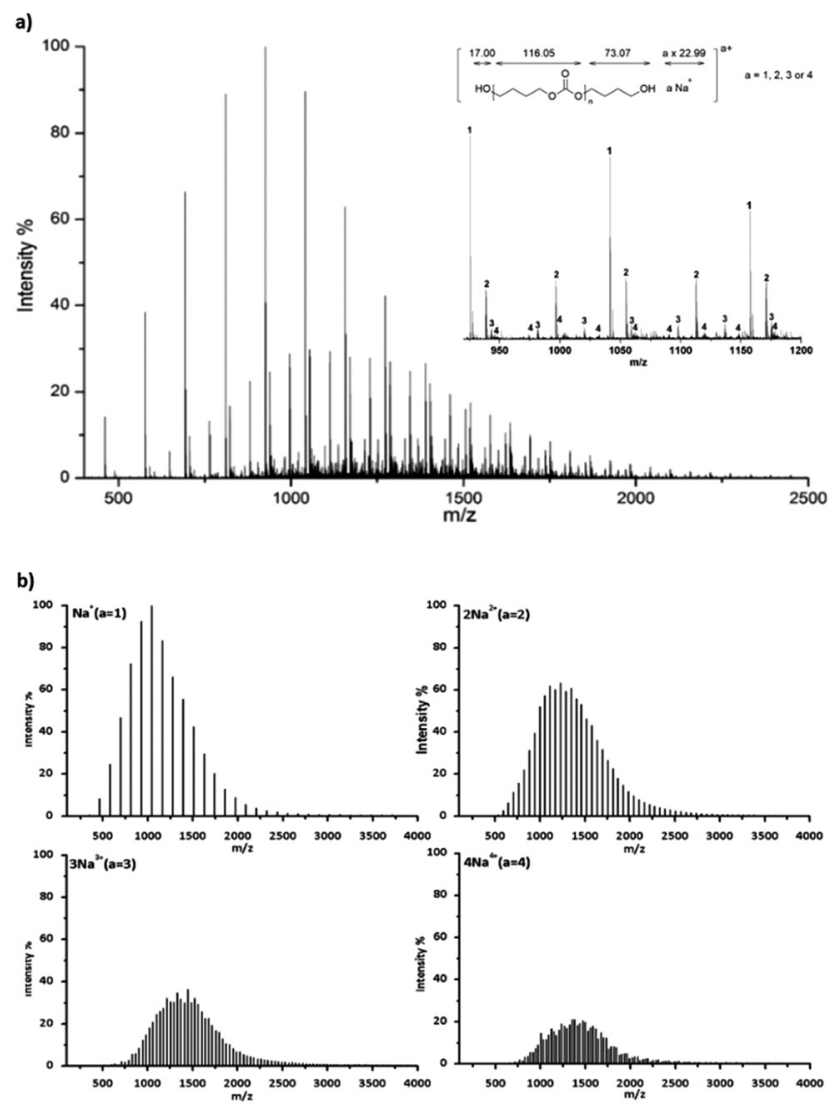

Fig. 4 ESI-TOF mass spectrum of PBC 7 (Table 2, entry 7) terminated with the hydroxyl group, (a) complete spectrum and a part of the spectrum distinguished by carrying charges $a=1,2,3$ and 4 in the region $\mathrm{m} / \mathrm{z} 400$ to 2500 , and (b) separated spectra with $a=1,2,3$ and 4 .
Table 3 Calculated and experimental $\mathrm{m} / \mathrm{z}$ in the ESI-TOF mass spectrum of PBC 7 with different charges (a up to 4 )

\begin{tabular}{llllll}
\hline$a$ & $\begin{array}{l}\text { Calculated } \\
{[\mathrm{Da}]}\end{array}$ & $\begin{array}{l}\text { Found } \\
{[\mathrm{Da}]}\end{array}$ & $\begin{array}{l}\text { Calculated } \\
{[\mathrm{Da}]}\end{array}$ & $\begin{array}{l}\text { Found } \\
{[\mathrm{Da}]}\end{array}$ & $\begin{array}{l}\text { Difference } \\
{[\mathrm{Da}]}\end{array}$ \\
\hline 1 & 1042.01 & $\begin{array}{l}1042.19 \\
(n=8)\end{array}$ & 1158.12 & $\begin{array}{l}1158.33 \\
(n=9)\end{array}$ & 116.14 \\
2 & 1229.19 & $\begin{array}{l}1229.36 \\
(n=20)\end{array}$ & 1287.24 & $\begin{array}{l}1287.37 \\
(n=21)\end{array}$ & 58.01 \\
3 & 1214.18 & $\begin{array}{l}1214.38 \\
(n=30)\end{array}$ & 1252.88 & $\begin{array}{l}1253.06 \\
(n=31)\end{array}$ & 38.68 \\
4 & 1206.67 & $\begin{array}{l}1206.86 \\
(n=40)\end{array}$ & 1235.69 & $\begin{array}{l}1235.91 \\
(n=41)\end{array}$ & 29.05 \\
& & & & &
\end{tabular}

Fig. 4a shows a typical ESI-TOF-MS spectrum for hydroxyl terminated PBC. Polymers were multiply charged during the ionization. The different series can be separated by Ion Mobility Separation (IMS). ${ }^{35}$ The separated spectra of up to tetraly charged polymers are shown in Fig. $4 \mathrm{~b}$. Moreover, the pentaly and hexaly charged polymers were also detected but they are distributed with low intensity. The ESI-TOF-MS spectra show the presence of the main series of polymer chains corresponding to (HO-PBC- $\left.\mathrm{C}_{4} \mathrm{H}_{8} \mathrm{OH} a \times \mathrm{Na}\right)^{a+}(a=1,2,3$ or 4$)$ with repeating units of $116.05 \mathrm{Da}$, which is the molar mass of the repeating PBC unit. For the doubly charged polymer with $n=$ 20 (Table 3, entry 2), the measured value of 1229.36 Da corresponded to the calculated value of 1229.19 Da using eqn (2). No further series could be seen, indicating that the polymer was only terminated with hydroxyl groups at both the chain ends. Hence, the organo-catalyzed synthesis of polycarbonates proceeded successfully without any side reaction, such as decarboxylation.

$$
m / z=\frac{\mathbf{M}(\mathrm{BD})+\mathbf{M}(\text { monomer unit }) \times n+a \times \mathrm{Na}^{+}}{a}
$$

The thermal properties of the PBC, PPC and PHC samples were evaluated by DSC as shown in Table 4 . The PBC samples displayed glass transition temperatures $\left(T_{\mathrm{g}}\right)$ of $-36-31^{\circ} \mathrm{C}$ and $T_{\mathrm{g}}$ increases with the increasing molar mass. The $T_{\mathrm{g}}$ of the PHC sample tended to lower $T_{\mathrm{g}}$ due to the higher chain flexibility. The melting temperatures $\left(T_{\mathrm{m}}\right)$ were observed at 56-62 ${ }^{\circ} \mathrm{C}$, while the PPC and PHC showed lower $T_{\mathrm{m}}$. In our case, the $T_{\mathrm{g}}$ was not visibly affected by the nature of the chain end group compositions.

Table 4 Thermal properties of aliphatic polycarbonate samples

\begin{tabular}{lcll}
\hline & $M_{\mathrm{n}}{ }^{a}\left(\mathrm{~g} \mathrm{~mol}^{-1}\right)$ & $T_{\mathrm{g}}{ }^{b}\left({ }^{\circ} \mathrm{C}\right)$ & $T_{\mathrm{m}}{ }^{b}\left({ }^{\circ} \mathrm{C}\right)$ \\
\hline PBC 5 & 7900 & $c$ & 59.9 \\
PBC 4 & 16000 & -35.9 & 61.6 \\
PBC 9 & 23000 & -33.2 & 59.0 \\
PBC 10 & 52000 & -31.9 & 56.4 \\
PPC 1 & 22000 & -42.4 & 54.2 \\
PHC 1 & 23000 & -38.6 & 55.5
\end{tabular}

${ }^{a}$ Determined using SEC in chloroform with PS standards. ${ }^{b} T_{\mathrm{g}}$ and $T_{\mathrm{m}}$ were measured by DSC. ${ }^{c}$ Not detected. 


\section{Conclusions}

In summary, we demonstrated that the commercially available organo-catalysts DMAP, PPY, TBD and MTBD were suitable for the synthesis of aliphatic polycarbonates with high molar masses and low dispersities via a two-step condensation polymerization under relatively mild operating conditions. Poly(1,4-butylene carbonate) (PBC), poly(1,5-pentamethylene carbonate) (PPC) and poly(1,6-hexamethylene carbonate) (PHC), were successfully prepared with $M_{\mathrm{n}}$ up to 23000 $\mathrm{g} \mathrm{mol}{ }^{-1}$, dispersities below 1.80 and yields of $>80 \%$ at $130{ }^{\circ} \mathrm{C}$ using 4-dimethylaminopyridine (DMAP) as the catalyst. At $170{ }^{\circ} \mathrm{C}$, the molar mass of poly(1,4-butylene carbonate) increased up to $52000 \mathrm{~g} \mathrm{~mol}^{-1}$.

In addition, according to our results, polycarbonates with a defined $M_{\mathrm{n}}$, end group composition and low dispersity could be achieved by changing the initial feed ratios, polymerization temperatures and catalysts with different activities. Remarkably, depending on the initial feed ratio $([\mathrm{BD}]:[\mathrm{DMC}]<1: 1.2)$, hydroxyl terminated polycarbonates with different molar masses can also be obtained with a high molar mass (up to $\left.17000 \mathrm{~g} \mathrm{~mol}^{-1}, D_{\mathrm{M}}=1.77\right)$. These materials are of great interest, because the combination with other polymerization methods, such as controlled radical polymerization (ATRP, RAFT or NMRP) for further application and thermal property improvement is allowed by end group modification. Additionally, the thiourea based organo-catalysts retarded the transesterification and condensation polymerization steps. On the other hand, this also proves why the thiourea based catalysts could be used in the ring opening polymerization of cyclic esters or carbonates and inhibiting simultaneously the transesterification side reaction.

\section{Acknowledgements}

The authors gratefully acknowledge the financial support from the German Ministry of Education and Research (BMBF Grand no. IB-070).

\section{References}

1 J. Feng, R. Zhuo and X. Zhang, Prog. Polym. Sci., 2012, 37, 211-236.

2 H. Schobert and C. Song, Fuel, 2002, 81, 15-32.

3 A. Davis and J. H. Golden, J. Macromol. Sci. Polym. Part C: Polym. Rev., 1969, 3, 49-68.

4 P. U. Naik, K. Refes, F. Sadaka, C.-H. Brachais, G. Boni, J.-P. Couvercelle, M. Picquet and L. Plasseraud, Polym. Chem., 2012, 3, 1475-1480.

5 A. Welle, M. Kröger, M. Döring, K. Niederer, E. Pindel and I. S. Chronakis, Biomaterials, 2007, 28, 2211-2219.

6 A. P. Pêgo, D. W. Grijpma and J. Feijen, Polymer, 2003, 44, 6495-6504.
7 W. Kuran, M. Sobczak, T. Listos, C. Debek and Z. Florjanczyk, Polymer, 2000, 41, 8531-8541.

8 L. S. Nair and C. T. Laurencin, Prog. Polym. Sci., 2007, 32, 762-798.

9 I. Engelberg and J. Kohn, Biomaterials, 1991, 12, 292-304.

10 W. H. Carothers and F. J. Van Natta, J. Am. Chem. Soc., 1930, 52, 314-326.

11 K. J. Zhu, R. W. Hendren, K. Jensen and C. G. Pitt, Macromolecules, 1991, 1736-1740.

12 X. Lu, W. Ren and G. Wu, Acc. Chem. Res., 2012, 45, 17211735.

13 D. J. Darensbourg and S. J. Wilson, Green Chem., 2012, 14, 2665.

14 K. Makiguchi, Y. Ogasawara, S. Kikuchi, T. Satoh and T. Kakuchi, Macromolecules, 2013, 46, 1772-1782.

15 M. Helou, O. Miserque, J.-M. Brusson, J.-F. Carpentier and S. M. Guillaume, Chem. - Eur. J., 2010, 16, 1380513813.

16 F. Nederberg, B. G. G. Lohmeijer, F. Leibfarth, R. C. Pratt, J. Choi, A. P. Dove, R. M. Waymouth and J. L. Hedrick, Biomacromolecules, 2007, 8, 153-160.

17 F. Suriano, O. Coulembier, J. L. Hedrick and P. Dubois, Polym. Chem., 2011, 2, 528-533.

18 S. Tempelaar, L. Mespouille, O. Coulembier, P. Dubois and A. P. Dove, Chem. Soc. Rev., 2013, 42, 1312-1336.

19 E. Foy, J. B. Farrell and C. L. Higginbotham, J. Appl. Polym. Sci., 2008, 111, 13-17.

20 J. Xu, E. Feng and J. Song, J. Appl. Polym. Sci., 2014, 131, 39822.

21 W. Zhu, X. Huang, C. Li, Y. Xiao, D. Zhang and G. Guan, Polym. Int., 2011, 60, 1060-1067.

22 J. H. Park, J. Y. Jeon, J. J. Lee, Y. Jang, J. K. Varghese and B. Y. Lee, Macromolecules, 2013, 46, 3301-3308.

23 S. Bigot, N. Kébir, L. Plasseraud and F. Burel, Polymer, 2015, 66, 127-134.

24 Q. Li, W. Zhu, C. Li, G. Guan, D. Zhang, Y. Xiao and L. Zheng, J. Polym. Sci., Part A: Polym. Chem., 2013, 51, 1387-1397.

25 H. Mutlu, J. Ruiz, S. C. Solleder and M. A. R. Meier, Green Chem., 2012, 14, 1728-1735.

26 W. Zhu, W. Zhou, C. Li, Y. Xiao, D. Zhang, G. Guan and D. Wang, J. Macromol. Sci., Pure Appl. Chem., 2011, 48, 583594.

27 H. R. Kricheldorf and A. Mahler, J. Polym.Sci., Part A: Polym. Chem., 1996, 34, 2399-2406.

28 H. R. Kricheldorf and A. Mahler, Polymer, 1996, 37, 43834388.

29 D. Delcroix, B. Martín-Vaca, D. Bourissou and C. Navarro, Macromolecules, 2010, 43, 8828-8835.

30 A. P. Dove, R. C. Pratt, B. G. G. Lohmeijer, R. M. Waymouth and J. L. Hedrick, J. Am. Chem. Soc., 2005, 103, 1379813799.

31 B. G. G. Lohmeijer, R. C. Pratt, F. Leibfarth, J. W. Logan, D. A. Long, A. P. Dove, F. Nederberg, J. Choi, C. Wade, R. M. Waymouth and J. L. Hedrick, Macromolecules, 2006, 39, 8574-8583. 
32 A. M. Goldys and D. J. Dixon, Macromolecules, 2014, 47, 34 C. B. Tripathi and S. Mukherjee, J. Org. Chem., 2012, 77, 1277-1284. $1592-1598$.

33 K. Ishihara, M. Niwa and Y. Kosugi, Org. Lett., 2008, 10, 35 J. Song, C. H. Grün, R. M. A. Heeren, H.-G. Janssen and O. F. 2187-2190. van den Brink, Angew. Chem., Int. Ed., 2010, 49, 10168-10171. 